remissions and exacerbations are frequent. A topical corticosteroid is most commonly used to treat this condition. If in doubt, it is necessary to consider, and rule out conditions such as allergic reaction to drugs, Henoch-Schonlein purpura and thrombocytopenia caused by a viral infection.

\section{AVOIDING DIFFERENT VACCINE, THROUGH PRISM OF FEAR FROM COVID, TO CHILDREN FROM THE CENTRAL REGION OF SERBIA}

${ }^{1} \mathrm{M}$ Gostiljac*, ${ }^{2} \mathrm{~N}$ Radonjić, ${ }^{2} \mathrm{~V}$ Nikolić, ${ }^{2} \mathrm{~V}$ Đukić, ${ }^{1} \mathrm{M}$ Marinković. ${ }^{1}$ Health center Kraljevo; ${ }^{2}$ Institut of Public Haelth Kraljevo

\subsection{6/archdischild-2021-europaediatrics.79}

Introduction Initiated by disagreement in attitudes, even of the most influential professors from different faculties, reading of immunology interpretation, disagreement in professional public, provoked avoiding getting vaccines; in spite of the fact that the highest level of science and civilization have been conditioned by vaccines.

The Aim of Paper

Comparison with unknown reasons for avoiding MMR vaccine, (2003-2017) and parents' behavior during Covid infection. Recognition the real families fear through prism of accepting, refusing 'non Covid' vaccine defined by the law inclusion of vaccine.

Materials and Methods Insight into documentation, cumulative indexes of vaccine avoiding; emphasis on, above all, avoiding MMR vaccine between first and second year of age. Analyses of dynamism and social card of Morbillae epidemic in 2017, comparison of appearance in Romania and Kosovo. Facts about complications. Insight into percentage scope of vaccination during Covid pandemic by law defined vaccines. Comparison of VI and XII months of 2020 for the region Kraljevo, Vrnjacka Banja and Raska.

Results of the Research

Avoiding vaccination by MMR in the period 2003-2016 resulted in 1008 cases, especially in 2015 and 2016 137,396. Appearance of Morbillae catches population of Gypsies and it spreads to domiciles. Clinical conditions without fatal results. Facts in VI and XII months deny fear from avoiding legally obliged vaccines. MMR vaccine in VI month $(52,29$ and $85,93 \%$ for II and VII year) in XII month $90,75 \%$ cumulative, which is still insufficient. For other diseases the level is higher: in XII month of 2020 (OPV 99,06\%, DiTe per 98,98\%, Haep B 100\%, Hib 94, 69\%, TBC 94, 69\%). In 2017/2018 Morbillae epidemic - 2165 infected, 13 egsitus, 76\% clinical condition without complications. In Romania there was a dramatic decrease of vaccinated from 2013-2015 - 83\%, fatal outcome in most cases - children 1 year of age.

Conclusion families fear caused by Covid did not result in avoiding common vaccine. The level of getting vaccine MMR does not guarantee eradication of Morbillae. Agreement with calendar of EU is necessary. Vaccination against HPV virus, Rota virus or Varicellae within EU is not uniformed. Prejudices present in public are still here, avoiding vaccination, mostly by MMR exists. Vaccination against Covid SARS virus is aggravated; resistance and anti vaccination campaigns are present. Fear is slowly getting away; arguments about advantages of vaccination can hardly be ignored.

\section{GENETICS HEART AND CARDIOVASCULAR INVOLVEMENT IN RUSSIAN PATIENTS WITH MUCOPOLYSACCHARIDOSIS: EFFECTS OF ENZYME REPLACEMENT THERAPY}

Nato Vashakmadze*, LS Namazova-Baranova, NV Zhurkova, GV Revunenkov. Pirogov Russian National Research Medical University

10.1136/archdischild-2021-europaediatrics.80

Mucopolysaccharidosis is a rare lysosomal storage disorder. Clinical phenotype is very variable. Patients usually have short stature, multiplex dysostosism, facial dysmorphism, cardiovascular abnormalities and other changes We study cardiovascular and heart findings in patients with mucopolysaccharidosis II (MPS II) and effect after enzyme replacement therapy (ERT). 55 boys were included in our study. Cardiac problem has 49

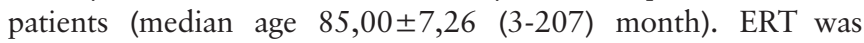
given to 46 patients since 2008 (median age 81,54 450,24 month).

Before ERT, mitral regurgitation had 27 patients, thickening of the mitral valve -17 , stenosis mitral valve 1 , aortic regurgitation - 20 patients, thickening of the aortic valve -6 , stenosis aortic valve -1 , tricuspid regurgitation 13 patients, pulmonary valve regurgitation -4 .

After ERT - mitral regurgitation had 35 patients, thickening of the mitral valve -20 , stenosis mitral valve -0 , aortic regurgitation - 23 patients, thickening of the aortic valve 35 , stenosis aortic valve -0 , tricuspid regurgitation -14 patients, pulmonary valve regurgitation -3 .

There were no statistically significant deterioration or improvement of the valve heart apparatus in the examined group of patients. $(\mathrm{P}>0,05)$.

Cardiomyopathy (left ventricular hypertrophy) have 6 boys with MPS II before and after ERT, lung hypertension - 2 cases before ERT, 4 - after. The course of heart failure in MPS is progressive and we evaluated the heart condition by functional class. We have identified significantly high performance functional class at first patient visit (I class - 44,4\% patients, II class - 44,4\%). After ERT (median age 81,54 $\pm 50,24$ month) $89 \%$ patients have no negative dynamics. It should be noted that most patients began receiving ERT at age 6-8 years old, they had severe somatic and neurological symptoms.

ERT is not able to reverse the cardiac damage, but provides stabilization of heart failure. Early initiation of ERT is a factor preventing severe heart disease in MPSII patients.

\section{$81 \quad$ PITT-HOPKINS SYNDROME}

OB Kondakova, DI Grebenkin, NV Zhurkova, TT Batysheva, AA Lialina, EV Khrustaleva, IV Kanivets. National Medical Research Center of Children's Health of the Ministry of Health of the Russian Federation, Moscow, Russian Federation

\subsection{6/archdischild-2021-europaediatrics.81}

Pitt-Hopkins syndrome is rare inherited disease, characterized by mental retardation, moderate to severe, autistic disorders, breathing problems, seizures, apnea, and distinctive facial features. Frequency of disease is between 1: $34000-1: 41$ 000 in newborn. Pitt-Hopkins syndrome (PTHS) is caused by deletions, duplication (30\%), lager deletion (30\%), point 